\title{
Exploring EFL Learners' Comments on Web-Based Peer Feedback: Local and Global Revisions
}

\author{
Abdullah Al Abri ${ }^{1}$ \\ ${ }^{1}$ English Language Centre, University of Technology and Applied Sciences, Nizwa, Oman \\ Correspondence: Abdullah Al Abri, English Language Centre, University of Technology and Applied Sciences, \\ Nizwa, Oman.
}

Received: May 2, 2021

Accepted: May 24, 2021

Online Published: May 28, 2021

doi: 10.5539/elt.v14n6p114

URL: https://doi.org/10.5539/elt.v14n6p114

\begin{abstract}
The purpose of this empirical study was to explore the interactional commenting patterns that EFL learners produced in web-based peer feedback and correlate them with the learners' writing achievement. The study employed a quasi-experimental design built on the Theory of Cognitive Apprenticeship (Collins, 1991), which gives emphasis on coaching (local revision) and scaffolding (global revision) processes. The context of the study was in a public university in Oman and 50 participants were involved in a selected range of online peer-feedback processes, synchronously and asynchronously. A paired samples t-test showed that students were able to improve their grammar range and accuracy in writing essays more than other scaling categories (e.g. content and organization). The results of the qualitative analysis indicated that students produced far more comments synchronously than asynchronously, and most of the students' exchanges were on forms. The findings of this study could be a practical reference for those who plan to cultivate the use of technology in peer feedback practice.
\end{abstract}

Keywords: global revision, local revision, web-based peer feedback, writing

\section{Introduction}

In contrast to face-to-face peer feedback, the implementation of peer feedback on a web-based platform allows students to picture their thinking and performance in writing despite thinking a complex process is not easily detected (Aydin \& Yildiz, 2014; Patel \& Russell, 2003). Web-based peer feedback provides students with an essential opportunity to observe their writing process documented online and engage them to interact collaboratively in addressing revisions and generating suggestions for better writing. This learner-learner interaction enables students to enhance their writing based on their peers' comments and suggestions, and therefore they are reciprocally motivated to provide comments on their peers' writing production (Chittum \& Bryant, 2014; Singh \& Holt, 2013). Other studies (Warschauer, 1996; Wu, 2006) stressed that this learning tool shows a constructive effect of online peer-correction on students' motivation, collaboration, and perception towards writing. The integration of web-based platform and peer feedback is an innovative writing practice leading to the online construction of a writing piece as it progresses through a cycle of writing, peer feedback and rewriting (Lin \& Yang, 2011). This study aimed at integrating technology into peer feedback practice in EFL learning environments to address the following questions:

1) What are the main focuses of the EFL students' comments in web-based peer feedback?

2) To what extent does web-based peer feedback improve the EFL students' essay writing quality?

\section{Literature Review}

A considerable body of research has investigated the use of web-based peer feedback in writing (Ho et al., 2020; Noroozi \& Hatami, 2019; Pham et al., 2020; Wahyudin, 2018). For example, Pham et al. (2020) investigated the usefulness of online peer feedback in writing among 40 Vietnamese university students. The study concluded that online peer feedback aided the students in improving their writing skill significantly. The study also indicated that the students were able to overcome some barriers like the distress of destroying the harmonious relationship, irritating conflicts and hurting their friends. On the other hand, Ho et al. (2020) carried out a comparative study that involved an experimental group (online peer feedback) and a control group (face-to-face peer feedback). The study's findings revealed that the students in the experimental group outperformed the students in the control group. Similarly, Zhang and McEneaney (2020) conducted a 15-week research study to analyse the differences between 
teacher feedback and peer feedback in writing among 198 major English students. The outcomes of the analyses showed that the peer feedback group demonstrated a significantly better writing performance improvement than the traditional teacher feedback group.

Noroozi and Hatami (2019) conducted a pre-test-post-test design with 42 higher education students who were asked to write an argumentative essay online. The findings of their study stated that the students were encouraged to revise their peer's writing scripts carefully and provide productive feedback, which led to improvement in their writing. Wahyudin (2018) conducted a study that attempted to explore the practice of online peer feedback among 81 undergraduate students who were taking an Essay Writing Course at an Indonesian university. The study revealed that the students enhanced their writing, and most of them tended to provide feedback on content and organisation. However, Wihastyanang et al. (2020) compared teacher feedback and peer feedback among 55 English Department students. They found that the students who experienced online feedback did not outperform the group which had the traditional feedback.

An increasing number of studies have examined the students' feelings and thoughts when they are engaged in online peer feedback. For example, Aghaee and Hansson (2013) conducted a study to develop thesis manuscript quality among postgraduate students. In their study, 260 anonymous peer reviews were completed and analysed. The findings showed that students welcomed the use of anonymity in giving feedback. The use of anonymity provoked meaningful critical feedback because students, in this case, were released from the social pressure, and they were able to express themselves freely without bearing in mind interpersonal factors (Aghaee \& Hansson, 2013). MacLeod (1999) emphasised that online feedback facilitated the students' discussion to make the students more genuine when giving comments. This happens because the reviewers are able to evaluate writing without having to face the writers, so the reviewers can develop comfort in stating their true thoughts of their peers' writing. Other studies (Ho \& Savignon, 2007; Tuzi, 2004) pointed out that online peer feedback provides flexibility for students as it helps to minimise stress. It relieves students who do not like to offer feedback in face-to-face settings because it allows them to propose remote feedback asynchronously at their comfortable convenience. Anonymous peer feedback can affect students' feelings by making them less shy, and they neglect fears in expressing their thoughts on their peers' writings (Coté, 2014). However, Allen and Katayama (2016) stressed that students were frustrated and conveyed unfairness in online peer feedback activities.

Chen et al. (2011) conducted a single-group with pre-test-post-test design study to examine the productivity of applying peer feedback for students' English writing through blogging. Their study concluded that students were motivated to collaborate socially, which helped them gradually enhance their writing. Baran et al. (2013) believed that learning could occur when students are engaged in activities that encourage them to share, exchange and discuss ideas related to the given task. Engstrom and Jewett (2005) conducted a literature review of studies related to peer feedback practice using technology. Their review stressed that students who were engaged in online peer feedback tend to be more independent about their learning.

\subsection{Local and Global Revisions}

Significant research has studied the types of revisions generated in peer feedback (Arnold et al., 2009; Aydin \& Yildiz, 2014; Hanjani \& Li, 2014; Saeed \& Ghazali, 2017; Woo et al., 2011). These studies have investigated two types of revision, which are local and global. Faigley and Witte (1981) defined local revision as making form changes in linguistic features like grammar, capitalization, punctuation and spelling. On the other hand, global revision is defined as making changes in style, organization, ideas and content (Faigley \& Witte, 1981). Both revisions play a vital role in developing English learners' writing skills (Woo et al., 2011). However, earlier well-known research evidence stated that global revision values more than local revision because it includes analyzing and evaluating content quality which needs higher-order thinking skills (Scardamalia \& Bereiter, 1987).

Literature shows that much research has been conducted to investigate the type of revision students provide when they are engaged in peer feedback practices (Arnold et al., 2009; Aydin \& Yildiz, 2014; Bradley et al., 2010; Hanjani \& Li, 2014; Kessler, 2009; Kost, 2011; Saeed \& Ghazali, 2017). Saeed and Ghazali (2017) and Bradley et al. (2010) found that students produced more exploratory comments on global areas than local. On the other hand, Hanjani and Li (2014) concluded that highlighting grammatical, vocabulary and mechanics errors covered the majority of feedback discussion, whereas minor attention paid to the textual level comments such as content, organization, cohesion and coherence.

Kessler (2009) employed peer feedback in a wiki platform for students in a Mexican university. His research findings indicated that students provide more comments on content and style rather than grammatical accuracy. Likewise, Kessler et al. (2012) stressed that students tend to focus more on meanings than forms. Kessler et al. 
(2012) examined EFL learners' behaviours in providing feedback using Google Docs. Their study concluded that students focused more on giving global revision, particularly on meaning, than local revision.

Arnold et al. (2009) investigated the types of revision that intermediate German students using wikis. Their findings indicated that students put more attention to meaning and provided little feedback on forms. However, in contradiction to these findings, Kost (2011) compared the number of changes in forms and meaning. Kost's (2011) findings stated that the number of meaning-preserving changes was far less than formal changes, and students fixed grammatical errors effectively and appropriately. The nature and type of task are assumed to impact students' attention, whether to focus on form or content (Aydin \& Yildiz, 2014). For example, in some cases, if the complexity of a text is high, this may force students to focus on content that demands cognition, and students are likely to ignore changes in forms (Skehan \& Foster, 2001).

Allen and Katayama (2016) studied the focus of peer feedback among six Japanese undergraduate students in a writing course. They triangulated data from writing samples, interviews and classroom observation. Their study stressed that students produced more feedback on linguistic features like grammar and punctuation than on content and style.

Razak and Saeed (2015) conducted qualitative research aimed to investigate online peer feedback among Arab EFL learners. The study targeted a heterogeneous group of 14 Arab university students from six countries: Egypt, Algeria, Syria, Yemen, Sudan, and Tunisia. The analyses of the study indicated that students perform several revision operations like addition, substitution, deletion, permutation, consolidation, and distribution on forms and contents of their peers' writing samples. However, the study pinpointed that students gave more revisions and comments on forms than on content.

Vahedipour and Rezvani's study (2017) administered a study to investigate the effectiveness of wiki-based peer feedback among 50 EFL students in an Iranian university. The study revealed that students welcomed wikis in peer feedback in writing and offered a constructive revision on grammatical accuracy. However, Wahyudin (2018) recently conducted research that attempted to explore the practice of online peer feedback among 81 undergraduate students taking an Essay Writing course in an Indonesian university. The study revealed that most students tend to provide feedback on content, organization and ideas.

\subsection{Wiki-Based Peer Feedback}

Much work on the potential of peer feedback on wikis has been carried out to investigate its feasibility in essay writing (Hsu, 2019; Hsu \& Lo, 2018; Iksan \& Halim, 2018; Kemp et al., 2019; Lutaaya et al., 2018; Ma, 2020; Vahedipour \& Rezvani, 2017; Wang, 2015). Hsu (2019), for example, observed the dialogue that students created when working collaboratively in giving peer review using wiki pages. The study concluded that the students were significantly able to provide comments on language-related more than content-related. They were able to resolve the writing issues raised by their peers successfully. Similarly, Ma (2020) explored how inter-group peer feedback on a wiki platform could contribute to L2 writing essays. The study indicated that peers supported the essays' authors with comments on content more than on language forms. The study concluded that wiki was a useful tool that could contribute to L2 writing effectively.

Kemp et al. (2019) revealed that language learners benefited from working on wiki collaboratively in developing their writing proficiency. Vahedipour and Rezvani (2017) divided 50 intermediate Iranian EFL learners into two groups, experimental and control groups, to investigate the effects of pen-and-paper and wiki-mediated peer feedback in nurturing grammatical accuracy in writing. The results pointed out that peer feedback on wikis achieved a better effect on improving grammatical accuracy in written products. In contrast, Hsu and Lo (2018) compared individual writing and wiki-mediated collaborative writing among EFL Learners at a Taiwanese university. The study included two classes with 26 students in each. One class was appointed as the wiki-collaborative writing group, while the other was the individual writing group. The results showed that wiki was superior to individual writing on promoting content quality and linguistic accuracy of writing.

Lutaaya et al. (2018) conducted an eight-week case study to examine wiki-based collaborative writing among 48 students at one university in Uganda. The study indicated that working on wiki helped students in enhancing their writing. Moreover, students received wiki-based peer feedback positively since it helped them better quality writing (Lutaaya et al., 2018). Wang (2015) compared between non-wiki writing environment and the wiki writing environment in a business writing course among 48 Taiwanese university students. The study concluded that the wiki group outperformed the non-wiki group in writing performance. The study revealed that students enjoyed working on wikis, and they could promote interest in learning writing via wiki. Iksan and Halim (2018) investigated the effect of face-to-face feedback and wiki-based feedback on lowering L2 writing anxiety. The 
study indicated that online peer feedback students expressed lower L2 writing anxiety compared to face-to-face feedback. Nami and Marandi (2014) examined wikis' impact in a writing course among 20 EFL learners in a private English language institute in Iran. The participants were engaged in a wiki-based forum for out-of-classroom discussion about English writing. The study revealed that students appreciated the use of wiki in writing, and their comments mostly focused on grammar, spelling and punctuation.

\subsection{Zone of Proximal Development Theory (Vygotsky, 1978)}

The literature has revealed that peer feedback is highly supported by theories that emphasise the social nature of language learning. According to social constructivism, learning entails exchanging, sharing, and negotiation, and it integrates two aspects, personal inner and social aspects. Thus, knowledge and skills in English can be developed through peer interaction since it gives students a significant opportunity to make social involvement and communication of aspects related to English. Vygotsky (1978) developed his view of the Zone of Proximal Development (ZPD) which he defined as "the distance between the actual developmental level as determined by independent problem solving and the level of potential development as determined through problem solving under adult guidance, or in collaboration with more capable peers" (p. 86).

For Vygotsky, peer interaction is significant to writing development since it provides students with a compelling opportunity to construct knowledge through social sharing and communication (Chen et al., 2011). ZPD stresses that the central role of social interaction among learners is that a more knowledgeable peer provides assistance to the less knowledgeable peer while engaged in a shared task. Vygotsky (1978) clarified that collaborative learning among students is essential for helping each student in advancing through his/her zone of proximal development (ZPD). He identified it as the gap between what the learner could accomplish alone and what he or she could accomplish in cooperation with others who are more skilled or experienced. In L2 writing classrooms, peer feedback tasks are likely to engage learners to provide revisions and corrections on each other's use of language (Storch, 2002; Swain \& Lapkin, 1998). Thereby, peer feedback is a powerful tool of writing that promotes cooperation, critical thinking, peer learning and dynamic participation towards a final draft of the writing. This strongly encourages the student to move forward through his/her zone of proximal development.

\section{The Purpose of Study}

Literature reveals a lack of studies conducted on web-based peer feedback in the Arab context Ezza (2010). Thereby, this study hopes to bridge this gap and create practical information about the employment of web-based peer feedback in Arab EFL process writing. It is anticipated that this study could offer information about the Arab EFL writing setting that would be valuable to English teachers interested in the Arab context. With much anticipation, the researcher hopes that the findings and the pedagogical implications of this study will produce satisfying results in future teaching and learning efforts in writing. At a broader level, the pedagogical implications could provide insights on how to implement collaborative writing projects. The study is suitable for a learning environment where students' L2 writing proficiency levels are varied, and technology has not significantly been applied to both teaching and learning.

\section{Method}

This study was conducted in the University of Technology and Applied Sciences - Nizwa (UTAS-Nizwa) in Oman. The English Foundation Programme in the university includes four courses which are Pre-elementary English (Level 1), Elementary English (Level 2), Intermediate English (Level 3) and Advanced English (Level 4).

This study targeted 50 students from Level 4 . The researcher was not able to assign individuals to the experimental group randomly. In some cases, because of the policy of the educational institutions, the researcher can't access the population to select individual randomly, so he/she has to use existing intact classrooms (Gay et al., 2014). The researcher of this study did not assign individuals randomly, but he randomly assigned an intact group.

\subsection{Research Design}

This study implemented a quasi-experimental design, precisely a one-group pre-test-post-test design. A pre-test (Writing task) was administered at the beginning of the study in which the participants were asked to write an essay of 250 words expressing their opinion on the topic of "getting daily homework from teachers" in 45 minutes. Then, the students were engaged in peer feedback activities on a wiki page for about ten weeks. Finally, the pre-test was conducted again as a post-test. Each script of the test was evaluated by two blind markers using the public version of IELTS task 2 writing criteria. The public version assesses writing based on four scoring scales: task response, coherence and cohesion, lexical resource and grammar range and accuracy. 


\subsection{Theory of Cognitive Apprenticeship (Collins, 1991)}

This study constructed online peer feedback based on the Theory of Cognitive Apprenticeship, which involves six cumulative processes for externalizing knowledge (Collins, 1991). So, as shown in Figure 1, the conceptual framework of this study engaged the participants into six processes: modelling, coaching, scaffolding, articulation, reflection, and exploration.

Because writing is mainly merged with interior processes, being able to identify how to convert one's thoughts into a visible writing product is significant in web-based peer feedback. Based on the processes applied in the web-based peer feedback in this study, the participants were provided with authorization to perform a variety of tasks. These tasks included observing peers' writing process, delivering reviews on lexical and discourse level, interacting efficiently with peers, identifying differences between one's original writing draft texts and those reviewed by peers and choose whether to take or discard peers' revisions.
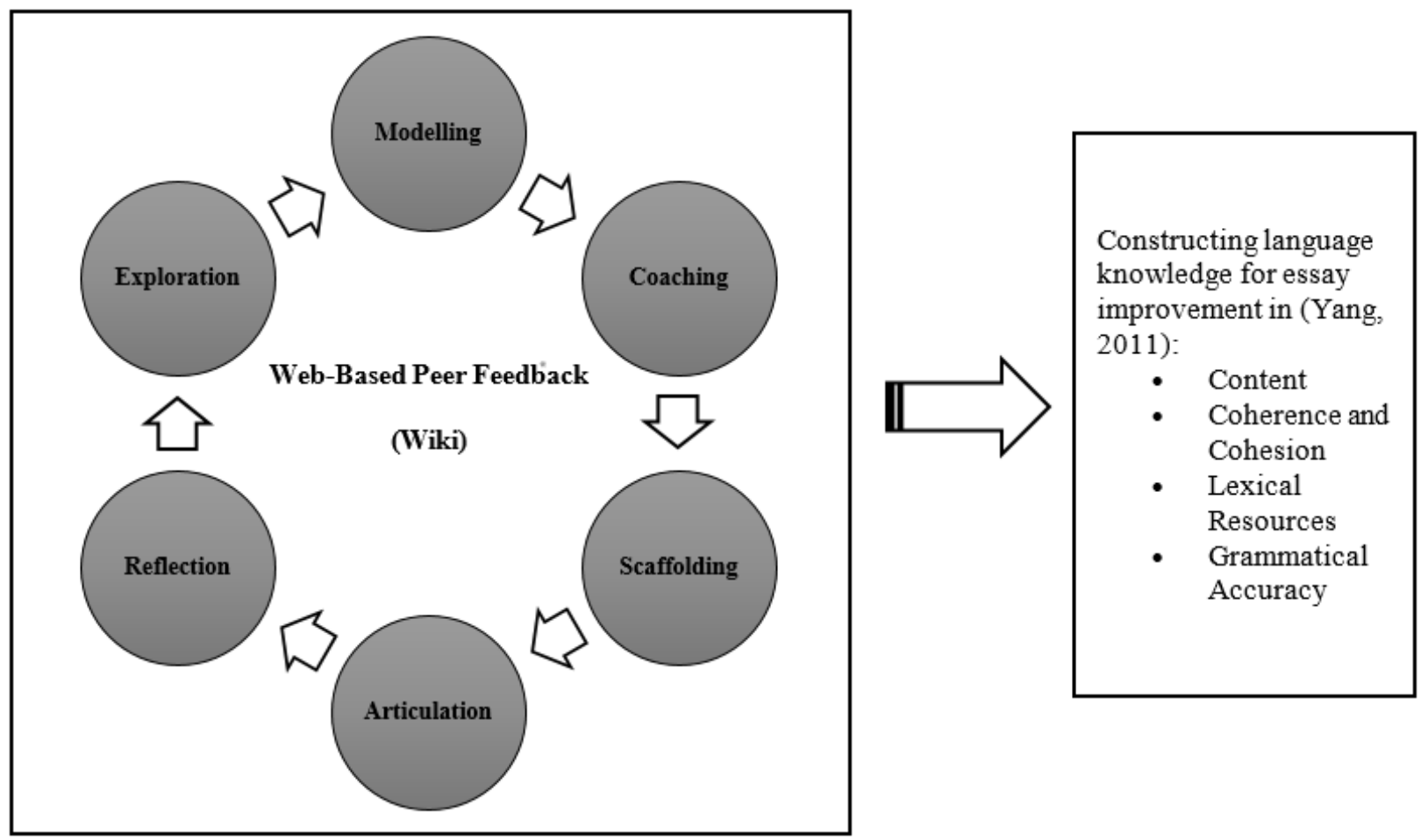

Figure 1. The Conceptual Framework of the Study

\subsubsection{Modelling}

In this process, all the participants' first drafts were posted on the web-based platform. With modelling, students could learn from other students reviewing skills more efficiently without struggling with mistakes (Collins, 1991; Wang, 2015). Furthermore, students had to be more attentive and responsible for revising others' texts because their reviews could also be models for others (Yang, 2011; Yoshimura, 2009).

\subsubsection{Coaching}

In the process of coaching, the participants were asked to provide local revision, which was direct corrections on the writing (Yang, 2011). Local revisions mainly focused on giving comments on linguistic features like grammar, spelling, punctuation and lexical usage. Collins (1991) asserted that the coaching process assists students in paying attention to areas that were previously ignored or temporarily neglected because there were not under the main focus in these stages. In fact, there is research evidence that proves that learners do not notice linguistic problems in writing (Li, 2006; Yang, 2011). Accordingly, this study on local revision was viewed as coaching since these mistakes are commonly unobserved by the writers themselves.

\subsubsection{Scaffolding}

In contrast to the coaching process, which emphasizes linguistic mistakes like grammar, scaffolding refers to global revision, which focuses on peers' comments and suggestions for student writers to reorganize their texts (Yang, 2011). In this stage, the participants were required to post comments on the development, organization or style of the essay they reviewed. By reading the global revision provided by peers, the students were encouraged to 
re-examine and reorganize their texts in terms of development, organization or style. Therefore, this allowed each student to delete or add a new paragraph or the reorganization of a full text.

\subsubsection{Articulation}

This process engages students in expressing their reasoning or problem-solving processes for each mistake, local or global (Yang, 2011). In this study, the reviewers were stimulated to make revisions and support each of their revisions with reasons.

\subsubsection{Reflection}

In this process, the participants were encouraged to make a comparison between their own problem-solving processes in writing with those of peers. This comparison helped students analyse their writing problems and adjust their revision strategies until they achieved the goal of text improvement (Yang, 2011). This comparison could lead to the examination of the past performances of both expert (reviewers) and novice students (reviewee) and to highlight similarities and differences.

\subsubsection{Exploration}

In this process, the students became more active and independent learners as they were encouraged to pick appropriate and effective peer review for improving their texts. Finally, the students were asked to rewrite their texts into final drafts based on their evaluation of the feedback from peers.

\subsection{The Validity and Reliability of the Pre and Post-Test}

A group of teachers who teach the Advanced English Course evaluated the face and content validity of the writing task (pre-test and post-test) and stated that the face and content validity is appropriate, clear and represents the course content. The researcher piloted the writing task to 30 participants to examine test-retest reliability, and the Pearson Correlation test of the collected data indicated that $(\mathrm{r}(30)=.82, \mathrm{p}=.00)$ this instrument has good reliability (Gay et al., 1992).

\section{Result Analyses}

\subsection{Students' Interactional Commenting Patterns}

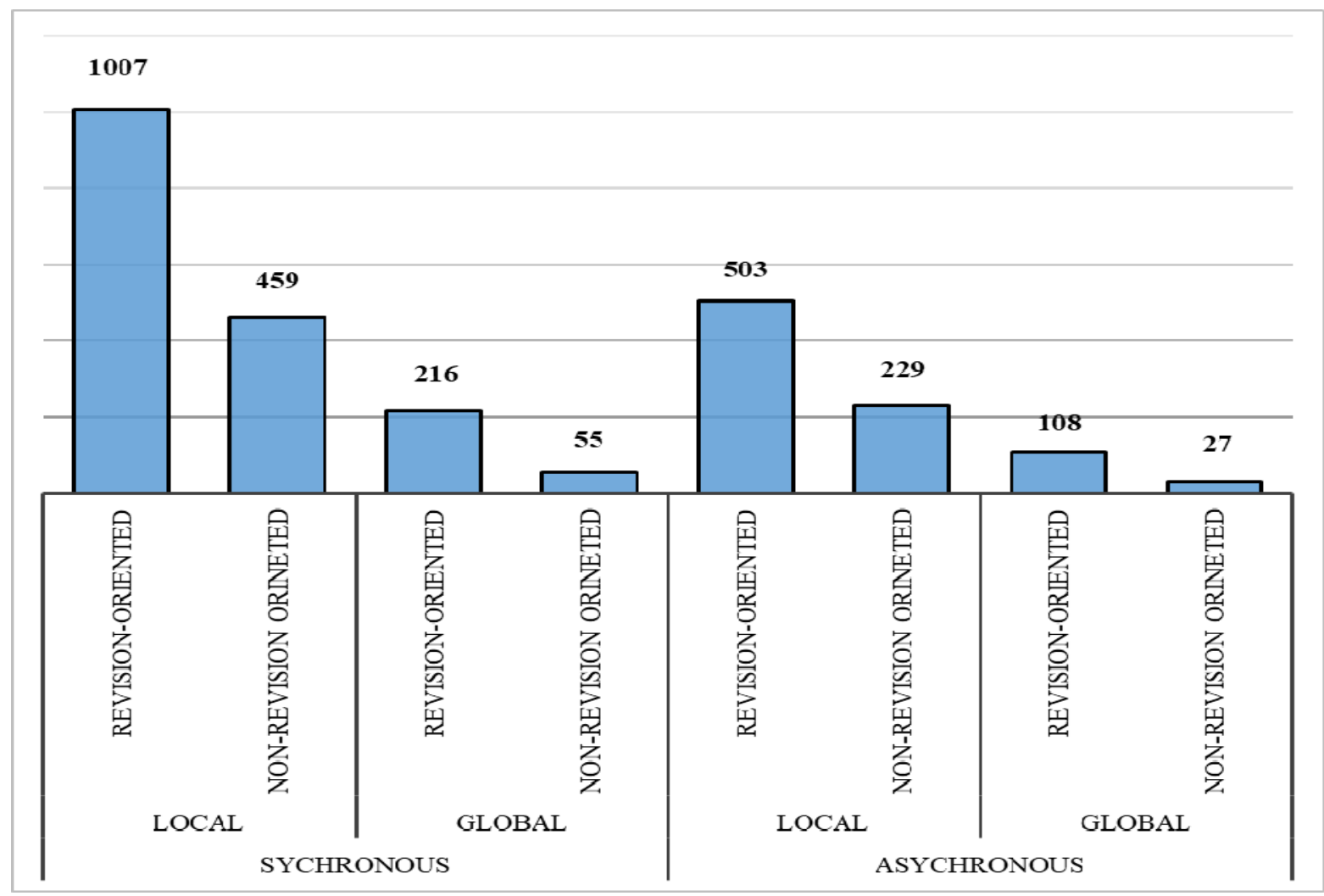

Figure 2. Numbers of Comments Created by the Students 
A qualitative analysis conducted to examine the types of comments the students exchanged when they were involved in the processes of coaching and scaffolding. As Figure 2 shows, the students exchanged comments on local and global revisions synchronously and asynchronously. The students posted a total of 2604 comments on the wiki page $(n=2604)$. The single most striking observation to emerge from this data comparison was that $66.7 \%$ of the comments $(n=1737)$ were generated synchronously compared to $33.3 \%$ asynchronously $(n=867)$. This gives a strong indication that students liked, or perhaps got excited, to exchange peer feedback when they realized their peers were available at the same moment. It is also interesting to note that students focused on commenting on forms (local revision) more than content (global revision); synchronously and asynchronously.

As stated above, students produced more comments when they were in the synchronous status. In this status, it is significantly apparent that $84.4 \%$ of the comments $(n=1466)$ emphasized local issues of the essays compared to $16.4 \%$ on global issues $(n=271)$. It worth mentioning that the exchanges the students generated were categorized into revision-oriented and non-revision-oriented exchanges. Excerpt 1 is extracted from the scaffolding process, and it shows the interaction that students created to discuss the use of the word "learn". The students AH and AJ provided revision-oriented comments by identifying mistakes in grammar and mechanics (Capitalization) and giving the correct forms. On the other hands, the students OM and WS produced non-revision-oriented exchanges by supporting or agreeing to $\mathrm{AH}$ and AJ's scaffolding comments.

wearing traditions clothes. One of the logical arguments is living in the simple life. In other words, life in the village is very simple and don't expensive and thar's make it children more happy. learn a good values is considered to be one of the solid argument. To make it simpleryou can find some of a great

\section{AH: Grammar mistake. We add -ing when it is in the beginning of the sentence.}

OM: I agree

AJ: Also mistake in CAP. L must be capital

WS: Totally agree. Thank you AJ and AH

It is obviously observed that the asynchronous statue was not active, in contrast to the synchronous statue. The $33.3 \%$ of exchanges made during this status $(n=867)$ were mostly on the scaffolding process (local revision). $84.4 \%$ of the comments $(n=732)$ were on local revision, while $15.6 \%$ were focused on global revision $(n=135)$.

\subsection{Writing Achievement}

Table 1. Results from Paired Samples T-Test

\begin{tabular}{llll}
\hline & $\mathrm{t}$ & $\mathrm{df}$ & Sig. (2-tailed) \\
\hline $\begin{array}{l}\text { Post-Content - } \\
\begin{array}{l}\text { Pre-Content } \\
\text { Post-Coherence-Cohesion } \\
\text {-Pre-Coherence-Cohesion }\end{array}\end{array}$ & 6.054 & 49 & .000 \\
$\begin{array}{l}\text { Post-Lexical-Resources - } \\
\text { Pre-Lexical-Resources }\end{array}$ & 7.92 & 49 & .000 \\
$\begin{array}{l}\text { Post-Grammar - } \\
\text { Pre-Grammar }\end{array}$ & 8.366 & 49 & .000 \\
\hline
\end{tabular}

Table 2. Means and Standard Deviation of Pre-Test and Post-Test

\begin{tabular}{llllll}
\hline \multirow{2}{*}{ Content } & & $\mathrm{N}$ & Mean & Std. Deviation & Std. Error Mean \\
\multirow{2}{*}{ Coherence and Cohesion } & Post-test & 50 & 6.8320 & .86954 & .12297 \\
& Pre-test & 50 & 6.5800 & .89875 & .12710 \\
\multirow{4}{*}{ Lexical Resources } & Post-test & 50 & 6.5900 & .91613 & .12956 \\
& Pre-test & 50 & 6.2140 & .87668 & .12398 \\
\multirow{2}{*}{ Grammatical Accuracy } & Post-test & 50 & 6.4860 & .95490 & .13504 \\
& Pre-test & 50 & 6.1620 & .90167 & .12752 \\
& Post-test & 50 & 6.2900 & .98897 & .13986 \\
\hline
\end{tabular}


Data obtained from the pre-test and post-test, as shown in Table 1 and Table 2, indicates that the post-test mean score in content $(M=6.83, S D=.87)$ was higher than pre-test $(M=6.58, S D=.90)$ conditions; $\mathrm{t}(49)=6.05 . \mathrm{p}=0.00$. Accordingly, there is evidence $(\mathrm{t}=6.05, \mathrm{p}=0.00)$ that online peer feedback improved students' scores in the content of their essays. In this data set, it improved scores, on average, by approximately 0.30 point on IELTS band descriptors.

For coherence and cohesion, Table 1 and Table 2 show that the post-test mean score $(M=6.59, S D=.92)$ was greater than pre-test mean score $(M=6.21, S D=.88)$ conditions; $\mathrm{t}(49)=9.11 . \mathrm{p}=0.00$. Therefore, there is clear evidence $(\mathrm{t}=9.11, \mathrm{p}=0.00)$ that peer feedback on the wiki platform improved students' scores in the coherence and cohesion of their essays by approximately 0.38 point, according to the IELTS band descriptors.

As presented in Table 1 and Table 2, the post-test mean score in lexical resources $(M=6.49, S D=.95)$ was higher than that mean score of pre-test $(M=6.16, S D=.90)$ conditions; $\mathrm{t}(49)=7.92, \mathrm{p}=0.00$. Given that, there is evidence $(\mathrm{t}=7.92, \mathrm{p}=0.00)$ that online peer feedback helped students improve their scores in the lexical resources of their essays. Specifically, it improved scores, on average, by approximately 0.32 point.

The post-test mean score in grammatical accuracy $(M=9.29, S D=0.99)$ was higher than the score obtained from pre-test $(M=5.88, S D=.90)$ conditions; $\mathrm{t}(49)=8.37, \mathrm{p}=0.00$. Therefore, there is clear evidence $(\mathrm{t}=8.37, \mathrm{p}=0.00)$ that students were able to improve their grammatical accuracy via peer feedback by 0.41 IELTS point.

\section{Discussion}

\subsection{Students’ Interactional Commenting Patterns}

This study investigated the types of comments that EFL learners generated in web-based peer feedback in writing. The results showed that students demonstrated a willingness to participate more in synchronous mode than asynchronous mode. The students posted more comments when they recognized that their peers were available online. The results also revealed that the majority of comments in both modes were on forms (local revision). These results matched those observed in earlier studies (Allen \& Katayama, 2016; Hanjani \& Li, 2014; Hsu, 2019; Kost, 2011; Nami \& Marandi, 2014; Razak \& Saeed, 2015) that students offered more comments on grammar, lexical resources, and mechanics like punctuation and capitalization. However, the current study's findings did not support the previous studies (Arnold et al., 2009; Bradley et al., 2010; Kessler, 2009; Kessler et al., 2012; Ma, 2020; Saeed \& Ghazali, 2017), which indicated more emphasis on content than forms.

\subsection{Writing Achievement}

In addition to investigating the students' interactional commenting patterns, this study explored to what extent web-based peer feedback improved the EFL learners' essay writing. The findings of this study are consistent with previous studies that the students showed development in their essay writing using their peers' comments and suggestions (Ho et al., 2020; Hsu, 2019; Hsu \& Lo, 2018; Iksan \& Halim, 2018; Lutaaya et al., 2018; Noroozi \& Hatami, 2019; Pham et al., 2020; Wang, 2015; Zhang \& McEneaney, 2020). These previous studies gave an overall impression that the students improved their writing. However, the analyses of this study offered a broader understanding of this development by pinpointing the specific areas that students were able to promote. Four categories of essay writing assess the students' performance: content, cohesion and coherence, lexical resources, and grammatical range and accuracy. The students improved their grammatical range and accuracy most, compared to other categories, using their peers' local and global revision comments. A possible explanation of the grammar improvement is that students provided far more comments on forms than content, synchronously and asynchronously.

Based on the sociocultural perspective (Vygotsky, 1978), peer interaction offers the learners a vital opportunity for building knowledge through social sharing and exchanging (Chen et al., 2011). This online learning environment this study generated assisted the students in promoting their ZPD. It was an encouraging environment, proving why students were more active in the synchronous mode than the asynchronous mode. The peer feedback practice provided the individual writer with a better understanding of the local and global issues in his/her writing. These issues were not easy to identify and solve without the peer's intervention (Chen et al., 2011; Ho et al., 2020).

\section{Conclusion}

This study explored the interactional commenting patterns that EFL learners generated in web-based peer feedback. The study also investigated how web-based peer feedback affected the EFL learners' writing proficiency. The most interesting finding was that students were more active and motivated in providing comments synchronously than asynchronously. The majority of comments they posted were on forms, and they showed limited attention to the textual level like content, organization, cohesion and coherence. The inferential statistics showed improvement 
in the students' writing proficiency in all the four scaling categories content, cohesion and coherence, lexical resources and grammatical range and accuracy. The students were able to improve their grammatical range and accuracy more than other categories of essay writing.

This study proved that web-based peer feedback is a practical pedagogy strategy that can help EFL learners enhance their knowledge of local and global issues for better writing quality. This study contributes to the existing knowledge by pinpointing specific areas of improvement in writing. However, the study offers no explanation why students posted more comments related to forms (local revisions) than content (global revision). Future research should therefore focus on identifying the possible rationale of preferring commenting on forms to content.

\section{Acknowledgement}

I would like to show my gratitude to the University of Technology and Applied Sciences - Nizwa (UTAS-Nizwa) for their collaboration and support in conducting this research project.

\section{References}

Aghaee, N., \& Hansson, H. (2013). Peer Portal: Quality enhancement in thesis writing using self-managed peer review on a mass scale. International Review of Research in Open Distributed Learning, 14(1), 186-203. https://doi.org/10.19173/irrodl.v14i1.1394

Allen, D., \& Katayama, A. (2016). Relative second language proficiency and the giving and receiving of written peer feedback. System, 56, 96-106. https://doi.org/10.1016/j.system.2015.12.002

Arnold, N., Ducate, L., \& Kost, C. (2009). Collaborative writing in wikis: Insights from culture projects in intermediate German classes. Retrieved from https://archives.pdx.edu/ds/psu/14564

Aydin, Z., \& Yildiz, S. (2014). Use of wikis to promote collaborative EFL writing. Language Learning and Technology, 18(1), 160-180.

Retrieved

from https://128.171.57.22/bitstream/10125/44359/18_01_aydinyildiz.pdf

Baran, E., Correia, A.-P., \& Thompson, A. (2013). Tracing successful online teaching in higher education: Voices of exemplary online teachers. Teachers College Record. Retrieved from https://www.learntechlib.org/p/156868/

Bradley, L., Lindström, B., \& Rystedt, H. (2010). Rationalities of collaboration for language learning in a wiki. ReCALL, 22(2), 247-264. https://doi.org/10.1017/S0958344010000108

Chen, Y. L., Liu, E. Z. F., Shih, R. C., Wu, C. T., \& Yuan, S. M. (2011). Use of peer feedback to enhance elementary students' writing through blogging. British Journal of Educational Technology, 42(1), E1-E4. https://doi.org/10.1111/j.1467-8535.2010.01139.x

Chittum, J. R., \& Bryant, L. H. (2014). Reviewing to Learn: Graduate Student Participation in the Professional Peer-Review Process to Improve Academic Writing Skills. International Journal of Teaching and Learning in Higher Education, 26(3), 473-484. Retrieved from https://files.eric.ed.gov/fulltext/EJ1060832.pdf

Collins, A. (1991). Cognitive apprenticeship and instructional technology (Vol. 1991).

Coté, R. A. (2014). Peer Feedback in Anonymous Peer Review in an EFL Writing Class in Spain. Gist Education and Learning Research Journal, 9, 67-87. https://doi.org/10.26817/16925777.144

Engstrom, M. E., \& Jewett, D. (2005). Collaborative learning the wiki way. TechTrends, 49(6), 12-15. https://doi.org/10.1007/BF02763725

Ezza, E.-S. (2010). Arab EFL learners' writing dilemma at tertiary level. English Language Teaching, 3(4). https://doi.org/10.5539/elt.v3n4p33

Faigley, L., \& Witte, S. (1981). Analyzing revision. College composition and communication, 32(4), 400-414. https://doi.org/10.2307/356602

Gay, L. R., Mills, G. E., \& Airasian, P. W. (1992). Educational research: Competencies for analysis and application.

Hanjani, A. M., \& Li, L. (2014). Exploring L2 writers' collaborative revision interactions and their writing performance. System, 44, 101-114. https://doi.org/10.1016/j.system.2014.03.004

Ho, M.-c., \& Savignon, S. J. (2007). Face-to-face and computer-mediated peer review in EFL writing. CALICO journal, 24(2), 269-290. https://doi.org/10.1558/cj.v24i2.269-290 
Ho, P. V. P., Phung, L. T. K., Oanh, T. T. T., \& Giao, N. Q. (2020). Should Peer E-Comments Replace Traditional Peer Comments? International Journal of Instruction, 13(1), 295-314. https://doi.org/10.29333/iji.2020.13120a

Hsu, H.-C. (2019). Wiki-mediated collaboration and its association with L2 writing development: an exploratory study. Computer Assisted Language Learning, $\quad 32(8), \quad$ 945-967. https://doi.org/10.1080/09588221.2018.1542407

Hsu, H.-C., \& Lo, Y.-F. (2018). Using wiki-mediated collaboration to foster L2 writing performance. Language Learning and Technology, 22(3), 103-123.

Iksan, H., \& Halim, H. A. (2018). THE EFFECT OF E-FEEDBACK VIA WIKIS ON ESL STUDENTS'L2 WRITING ANXIETY LEVEL. MOJES: Malaysian Online Journal of Educational Sciences, 6(3), 30-48. Retrieved from https://mojes.um.edu.my/article/view/12218

Kemp, C., Li, P., Li, Y., Ma, D., Ren, S., Tian, A., Wang, D., Xie, L., You, J., \& Zhang, J. (2019). Collaborative Wiki Writing Gives Language Learners Opportunities for Personalised Participatory Peer-Feedback. In Yu S., Niemi H., \& Mason J. (Eds.), Shaping Future Schools with Digital Technology (pp. 147-163). Springer. https://doi.org/10.1007/978-981-13-9439-3_9

Kessler, G. (2009). Student-initiated attention to form in wiki-based collaborative writing. Language Learning and Technology, 13(1), 79-95. Retrieved from https://128.171.57.22/bitstream/10125/44169/13_01_kessler.pdf

Kessler, G., Bikowski, D., \& Boggs, J. (2012). Collaborative writing among second language learners in academic web-based projects. Language Learning and Technology, 16(1), 91-109. Retrieved from https://128.171.57.22/bitstream/10125/44276/16_01_kesslerbikowskiboggs.pdf

Kost, C. (2011). Investigating writing strategies and revision behavior in collaborative wiki projects. CALICO journal, 28(3), 606-620. https://doi.org/10.11139/cj.28.3.606-620

Li, J. (2006). The mediation of technology in ESL writing and its implications for writing assessment. Assessing Writing, 11(1), 5-21. https://doi.org/10.1016/j.asw.2005.09.001

Lin, W.-C., \& Yang, S. C. (2011). Exploring students' perceptions of integrating Wiki technology and peer feedback into English writing courses. English Teaching: Practice and Critique, 10(2), 88-103.

Lutaaya, J. N., Cronje, J., \& Aheto, S.-P. K. (2018). Exploring Wiki-Based Collaborative Writing Activities among ESL Pre-Service Education Students. International Conference on e-Learning.

Ma, Q. (2020). Examining the role of inter-group peer online feedback on wiki writing in an EAP context. Computer Assisted Language Learning, 33(3), 197-216. https://doi.org/10.1080/09588221.2018.1556703

MacLeod, L. (1999). Computer-aided peer review of writing. Business Communication Quarterly, 62(3), 87-94. https://doi.org/10.1177/108056999906200309

Nami, F., \& Marandi, S. S. (2014). Wikis as discussion forums: exploring students' contribution and their attention to form. Computer Assisted Language Learning, 27(6), 483-508. https://doi.org/10.1080/09588221.2013.770036

Noroozi, O., \& Hatami, J. (2019). The effects of online peer feedback and epistemic beliefs on students' argumentation-based learning. Innovations in Education and Teaching International, 56(5), 548-557. https://doi.org/10.1080/14703297.2018.1431143

Patel, A., \& Russell, D. (2003). Cognitive Apprenticeship Learning-Ensuring Far Transfer of Knowledge Through Computer-Based Assessment. In S. Naidu (Ed.), Learning \& Teaching with Technology Principles \& Practices (pp. 233-246). Kogan Page. Retrieved from https://hdl.handle.net/2086/10220

Pham, T. N., Lin, M., Trinh, V. Q., \& Bui, L. T. P. (2020). Electronic Peer Feedback, EFL Academic Writing and Reflective Thinking: Evidence From a Confucian Context. SAGE Open, 10(1). https://doi.org/10.1177/2158244020914554

Razak, N. A., \& Saeed, M. A. (2015). EFL Arab Learners' Peer Revision of Writing in a Facebook Group: Contributions to Written Texts and Sense of Online Community. English Language Teaching, 8(12), 11-26. https://doi.org/10.5539/elt.v8n12p11

Saeed, M. A., \& Ghazali, K. (2017). Asynchronous group review of EFL writing: Interactions and text revisions. Language Learning and Technology, 21(2), 200-226. Retrieved from https://hdl.handle.net/10125/44618 
Scardamalia, M., \& Bereiter, C. (1987). Knowledge telling and knowledge transforming in written composition (Vol. 1). Cambridge University Press.

Singh, V., \& Holt, L. (2013). Learning and best practices for learning in open-source software communities. Computers and Education, 63, 98-108. https://doi.org/10.1016/j.compedu.2012.12.002

Skehan, P., \& Foster, P. (2001). Cognition and tasks. Cognition and second language instruction, 183, 205. https://doi.org/10.1017/CBO9781139524780.009

Storch, N. (2002). Patterns of interaction in ESL pair work. Language learning, 52(1), 119-158. https://doi.org/10.1111/1467-9922.00179

Swain, M., \& Lapkin, S. (1998). Interaction and second language learning: Two adolescent French immersion students working together. The modern language journal, 82(3), 320-337. https://doi.org/10.1111/j.1540-4781.1998.tb01209.x

Tuzi, F. (2004). The impact of e-feedback on the revisions of L2 writers in an academic writing course. Computers and composition, 21(2), 217-235. https://doi.org/10.1016/j.compcom.2004.02.003

Vahedipour, Z., \& Rezvani, E. (2017). Impact of Wiki-based Feedback on Grammatical Accuracy of Iranian EFL Learners' Writing Skill. International Journal of Foreign Language Teaching and Research, 5(20), 111-124.

Vygotsky, L. (1978). Interaction between learning and development. Readings on the development of children, 23(3), 34-41. Retrieved from https://luria.ucsd.edu/tclearninglounge/ROOT/carlos/readings/vygotsky_learning_and_dev.pdf

Wahyudin, A. Y. (2018). THE IMPACT OF ONLINE PEER FEEDBACK ON EFL STUDENTS WRITING AT TERTIARY LEVEL. BAHTERA: Jurnal Pendidikan Bahasa dan Sastra, 17(1), 1-10. https://doi.org/10.21009/BAHTERA.171.1

Wang, Y.-C. (2015). Promoting collaborative writing through wikis: A new approach for advancing innovative and active learning in an ESP context. Computer Assisted Language Learning, 28(6), 499-512. https://doi.org/10.1080/09588221.2014.881386

Warschauer, M. (1996). Computer-assisted language learning: An introduction. Multimedia language teaching, 320.

Wihastyanang, W. D., Kusumaningrum, S. R., Latief, M. A., \& Cahyono, B. Y. (2020). Impacts of Providing Online Teacher and Peer Feedback on Students' Writing Performance. Turkish Online Journal of Distance Education, 21(2), 178-189. https://doi.org/10.17718/tojde.728157

Woo, M., Chu, S., \& Li, X. (2011). Tracing peer feedback to revision process in a wiki supported collaborative writing. The Asian Conference on Education Official Conference Proceedings 2010.

Wu, W.-S. (2006). The effect of blog peer review and teacher feedback on the revisions of EFL writers. Journal of Education and Foreign Languages and Literature, 3(2), 125-138.

Yang, Y. F. (2011). A reciprocal peer review system to support college students' writing. British Journal of Educational Technology, 42(4), 687-700. https://doi.org/10.1111/j.1467-8535.2010.01059.x

Yoshimura, F. (2009). Effects of connecting reading and writing and a checklist to guide the reading process on EFL learners' learning about English writing. Procedia-Social and Behavioral Sciences, 1(1), 1871-1883. https://doi.org/10.1016/j.sbspro.2009.01.330

Zhang, X., \& McEneaney, J. E. (2020). What Is the Influence of Peer Feedback and Author Response on Chinese University Students' English Writing Performance? Reading Research Quarterly, 55(1), 123-146. https://doi.org/10.1002/rrq.259

\section{Copyrights}

Copyright for this article is retained by the author(s), with first publication rights granted to the journal.

This is an open-access article distributed under the terms and conditions of the Creative Commons Attribution license (http://creativecommons.org/licenses/by/4.0/). 